\title{
Prevalence and Associated Risk Factors of Hypertension Among People Aged 50 years and more in Banepa Municipality, Nepal
}

\author{
Manandhar $\mathrm{K},{ }^{1}$ Koju $\mathrm{R},{ }^{2}$ Sinha NP, ${ }^{1}$ Humagain $\mathrm{S}^{2}$
}

\author{
${ }^{1}$ Department of Community Medicine \\ ${ }^{2}$ Department of Medicine \\ Katmandu University, School of Medical Sciences \\ Dhulikhel Hospital - Kathmandu University Hospital \\ Dhulikhel, Kavre, Nepal
}

\section{Corresponding Author}

Kedar Manandhar

Department of Community Medicine

Katmandu University, School of Medical Sciences

Dhulikhel Hospital - Kathmandu University Hospital

Dhulikhel, Kavre, Nepal

Email: manandhark2@gmail.com

\section{Citation}

Manandhar K, Koju R, Sinha NP, Humagain S. Prevalence and Associated Risk Factors of Hypertension Among People Aged 50 years and more in Banepa Municipality Nepal. Kathmandu Univ Med J 2012;39(3):35-38.

\begin{abstract}
Background

Hypertension is a cardiovascular disorder rapidly emerging as a major public health problem in developing countries and is the most widely recognized modifiable risk factor for cardiovascular diseases.
\end{abstract}

\section{Objective}

The objective of this study was to find out the prevalence and associated risk factors with hypertension among people aged 50 years and more in Banepa Municipality, Kavre, Nepal.

\section{Methods}

It is a cross- sectional, population based study which was carried out in Banepa Municipality from May 15 to June 15, 2009. Among total 11 wards of Banepa municipally, wards number $1,3,5,6,7$, and 10 were selected by using Simple Random Sampling Technique and 405 subjects of people aged 50 years and more were selected for study from the selected wards by using Cluster Sampling. The structured interview method was used for collection of data. Mercury sphygmomanometers with standard cuff were used to measure the indirect auscultatory arterial blood pressure. Two consecutive blood pressure readings were taken and average of them was calculated to determine single value of blood pressure.

\section{Results}

The prevalence of hypertension was 44.9 percent $(47.75 \%$ in male and $42.73 \%$ in females). Among them, only 32.9 percent (60/182) were previously diagnosed as hypertension. The higher proportion of hypertensive cases were in age $>65$ years $(55.49 \%)$ than in the age group $<65$ years $(36.32 \%)$. The prevalence of hypertension was seen positively associated with non vegetarian eating habits, alcohol consumption, and $>25$ Body max index. Taking green leafy vegetable at least once a week was negatively associated with the prevalence of the hypertension.

\section{Conclusion}

These findings provide important information on the prevalence, associated factors of hypertension in Banepa Municipality. Effective public health measures and strategies are needed to improve prevention, diagnosis and access to treatment of these 50 years and above population.

\section{KEY WORDS}

Associated risk factors, cardiovascular disease, hypertension, prevalence 


\section{INTRODUCTION}

Hypertension is the leading cause of cardiovascular disease worldwide. Recent studies demonstrate that there is a linear correlation between blood pressure and cardiovascular events. ${ }^{1}$ Hypertension is also a major cause of disability, causing an estimated $13 \%$ of all deaths in the world. ${ }^{2}$ The treatment of high blood pressure can reduce cardiovascular morbidity and mortality. ${ }^{3}$ The first hypertension survey in Nepal was done in 1982 by Mrigendra Samjhana Medical Trust (MSMT) and the prevalence rate was six percent according to the old WHO criteria 160/95. ${ }^{4}$ After 25 years, repeat scientific survey was done by Nepal Hypertension Society in collaboration with MSMT in 2007. ${ }^{5}$ A study of prevalence, awareness and control of hypertension in a suburban area of Kathmandu, Nepal also showed that the prevalence of the hypertension in age group $>40$ years was $40 \% .^{6}$ The prevalence of hypertension in this age group has not well studied in Nepal. This study was performed to estimate the prevalence among people aged 50 years in Banepa municipality.

\section{METHODS}

This cross sectional, population based study was carried out in Banepa Municipality from May 15 to June 15, 2009. Among total 11 wards of Banepa municipality, ward numbers $1,3,5,6,7$, and 10 were selected by using Simple Random Sampling Technique and 405 subjects (all people aged 50 years and more available in the household during data collection time) were included for study from the selected wards by using Cluster Sampling Technique. The sample size was calculated with the formula $4 \mathrm{pq} / \mathrm{d} 2$. Where $\mathrm{p}$ is taken $50 \%$ and $\mathrm{d}$ is taken $10 \%$ of $\mathrm{p}$. Three well- trained nurses and research assistants collected data through home visit using a pre-tested structured questionnaire. The sociodemographic characteristics and health behavior related information were collected by using a structured interview with subjects. The questionnaire consisted of three parts.

- $\quad$ The first part of questionnaire concerned sociodemographic characteristics including age, sex, marital status, education, and occupation.

- $\quad$ The second part gathered data on health behavior including cigarette smoking, alcohol consumption, and eating habits.

- $\quad$ The third part collected data about body height $(\mathrm{BH})$, body weight (BW) and blood pressure (BP) of subjects.

A mercury sphygmomanometer with standard cuff was used to measure the indirect auscultatory arterial blood pressure. Two consecutive blood pressure readings were taken from the right arm with subject in a sitting position. Average of them was calculated to determine single value of blood pressure. Subject was considered as hypertensive if any of the following conditions were met - average Systolic Blood Pressure (SBP) $>140 \mathrm{~mm} \mathrm{Hg}$ or Diastolic
Blood pressure (DBP) $>90 \mathrm{~mm} \mathrm{Hg}$ or if they have used antihypertensive drugs (JNC 7 Criteria). ${ }^{7}$

\section{Current Smoker}

Current smoker was defined as a subject who has smoked cigarettes or taken any form of tobacco within one month and is still smoking.

\section{Ex-Smoker}

Ex- smoker was defined as a subject who had previously smoked more than 100 cigarettes but had quit for more than one month.

\section{Current Drinker}

Current Drinker was defined as a subject who has consumed alcohol in the last month and still consuming. The current drinkers were categorized in to regular and occasionally drinker. The regular drinker was considered who has consumed alcohol every day in the last month and who has consumed few days (less than a week) of last month was considered as occasionally drinker.

All data were entered on database and analyzed using SPPS-16. Variables were coded, decoded to simplify the process of data entry and analysis. All continuous variables, including age, body weight, body mass index (BMI), and blood pressure were expressed as mean, and standard deviation. The risk factors of hypertension were analyzed by using chi- square test. All $p$-values less than 0.05 were considered statistically significant.

\section{RESULTS}

Among 405 subjects, 56 percent were female (table 1). The mean age of subjects was $63.6+10.1$ years with their ages ranging from 50 to 99 years. Among the total subjects, 55.1 percent of them were age group ( $<65$ years) and remaining (44.9\%) of them were from old age group (>65 years) (table 2). Sixty percent of subjects were engaged in their household activities and 90.1 percent of the subjects were non-vegetarian. Among the total subjects, 33.1 percent were alcohol consumers and 59 percent (79/134) of them consumed it occasionally while 26 percent consumed Table 1. Socio-demographical variable $(n=405)$.

\begin{tabular}{ll} 
Variable & Number $(\%)$ \\
\hline Gender & \\
\hline Male & $178(44)$ \\
\hline Female & $227(56)$ \\
\hline Age & \\
\hline$<65$ years & $223(55.1)$ \\
$>65$ years & $182(44.9)$
\end{tabular}

regularly and rest 15 percent of them consumed once time a week.

The study revealed that 44.9 percent $(182 / 405)$ of subjects were hypertensive. Among them, only 32.9 percent (60/182) had been diagnosed as hypertension. The prevalence was 
Table 2. Prevalence of Hypertension ( $n=405)$.

\begin{tabular}{ll}
\hline Variable & Number (\%) \\
\hline Hypertensive cases & $182(44.9)$ \\
\hline Normal cases & $223(55.1)$ \\
\hline Total & $405(100.0)$ \\
\hline
\end{tabular}

Table 3. Prevalence of Hypertension and associated factors $(n=405)$.

\begin{tabular}{lcll}
\hline $\begin{array}{l}\text { Variable } \\
\text { Gender }\end{array}$ & Variable & $\begin{array}{l}\text { Hypertensive } \\
\text { case Number (\%) }\end{array}$ & P value \\
\hline $\begin{array}{l}\text { Male } \\
\text { Female }\end{array}$ & 178 & $85(47.7)$ & 0.317 \\
\hline Age & 227 & $97(42.7)$ & \\
\hline$<65$ years & 223 & $81(36.3)$ & \\
\hline$>65$ years & 182 & $101(55.4)$ & $<0.001$ \\
\hline Body Max Index (Kg/M2) & & \\
\hline$>25$ & 156 & $85(54.4)$ & 0.002 \\
\hline$<25$ & 249 & $97(38.9)$ & \\
\hline Current smoking habit & & \\
\hline Yes & 95 & $37(38.9)$ & 0.196 \\
\hline No & 310 & $145(46.8)$ & \\
\hline Current alcohol consumption habit & \\
\hline Yes & 134 & $72(53.7)$ & 0.012 \\
\hline No & 271 & $110(40.6)$ & \\
\hline Types of diet & & $172(47.2)$ & 0.005 \\
\hline Non vegetarian & 364 & $10(24.3)$ & \\
\hline Vegetarian & 41 & & \\
\hline
\end{tabular}

slightly higher in males (47.75\%) than females (42.73\%) but the differences observed between male and female were not statistically significant $(p=0.317)$ (table 3$)$. More hypertensive cases were in those age $>65$ (55.49\%) than in the age group $<65$ (36.32\%). The differences of the prevalence rate between these age groups were found statistically significant ( $p=<0.001$ ) (table 3 ).

The significant higher percentage of hypertensive cases were seen in non-vegetarian eating habits $(p=0.005)$, current alcohol consumption ( $p=0.012$ ), and $>25 \mathrm{BMI}$ ( $p$ $=0.002$ ). Slightly higher proportion of hypertensive cases were seen in the non smokers as compared to currently smokers but difference between these groups were not statistically significant $(p=0.196)$. But significantly lower cases of hypertensive were seen in respondents who had habits of taking green leafy vegetable at least once a week $(p=0.022)$.

\section{DISCUSSION}

Hypertension is a common health problem in developing countries and prevalence is currently raising steadily. ${ }^{2}$ The prevalence of hypertension in people aged 50 years and more in this study was $44.9 \%(47.75 \%$ in male and $42.73 \%$ in females). The study conducted by Panday et al. in 1981 showed that overall prevalence was only $5.98 \%$ in rural population in Nepal. But a study conducted by Sharma et al in 2005 sub urban area of Kathamdu, Nepal revealed that prevalence of hypertension among people aged 50 years and above was around $42 \%$. The study in rural Kathmandu conducted by Vaidya et al in 2006 indicated that the prevalence of hypertension in Nepal has been in the increasing trend. ${ }^{5}$ The same kinds of trend was also experienced in India. ${ }^{8}$

Various studies have shown that hypertension is more prevalent in men compared to women. ${ }^{9-11}$ However, some other studies showed female preponderance. ${ }^{12-16}$ Our present study revealed that HTN is slightly higher in male, but differences between these two groups were statistically not significant $(p=0.317)$. The variation may be explained by differential distribution in risk factors (e.g. genetic predisposing, dietary factors, and lack of physical activities).

Age is strongly associated with hypertension. In many studies, it was reported that prevalence of hypertension increases with age. ${ }^{13,14}$ In this study also showed that the prevalence of hypertension among age $>65$ years $(55.4 \%)$ was significantly higher than age group $<65$ years $(36.3 \%)$.

Several studies have also found that obesity is principal risk factor for development of hypertension.${ }^{17}$ Overweight or obesity was significantly associated with hypertension. ${ }^{18}$ In this study, 54.4 percent subjects who have $>25 \mathrm{BMI}$ were hypertensive whereas only 28.9 percent subjects with $<25$ BMI were hypertensive. This study demonstrated that obesity was also a serious public health problem in urban area of Nepal. A serious educational effort about obesity and its risks should be made for the population.

Current smoking is significant independent risk factor for hypertension in both male and female. ${ }^{15,16}$ In other studies, significant association between hypertension and smoking has not been observed. ${ }^{19,20}$ This study also revealed less frequent of hypertension in current smokers (38.9\%) than non smokers $(46.8 \%)$. But it is not statistically significant $(p=0.196)$. It is important to indicate that our data, similar to other studies, have shown the interesting phenomenon that current smokers have lower cases than non smokers. Alcohol is one of many important life style related factors implicated in the genesis of hypertension. This research revealed that hypertension was significantly increased in subjects with habits of alcohol consumption.

The study showed the increased trend of prevalence of hypertension in comparison to earlier studies and different risk factors identified in this study indicates that adoption of westernized life styles and exposure to stress of acculturation and modernization might be the reason for such a phenomenon. Policymakers should develop strategies for the prevention and control of the increasing trend of hypertension considering these findings.

Some limitations of this study should be mentioned: first 
the use of a single visit to ascertain hypertension status can result in an over-estimation of its prevalence. Other

Potential sources of bias include the self-reported health related behaviors so under and over reporting is expected.

\section{CONCLUSION}

Our findings provide important information on the prevalence, and associated risk factors of hypertension. Near to than half of our study population was classified as hypertensive but only one third of them was previously diagnosis as hypertension.

The prevalence of hypertension was seen positively associated with non vegetarian eating habits, alcohol consumption, and > 25 BMI. Taking green leafy vegetable

\section{REFERENCES}

1. Lee DS, Massaro JM, Wang TJ, Kannel WB, Benjamin EJ, Kenchaiah $S$ et.al. Antecedent blood pressure, body mass index and the risk of incident heart failure in later life. Hypertension 2007;50:869-876.

2. World Health Organization: Global Health risks; Mortality and Burden of disease attributable to Selected Major Risks. Geneva: World Health Organization Press; 2009.

3. Staessen JA, Wang JG, Thijs L. Cardiovascular protection and blood pressure reduction: a meta analysis. Lancet 2001; 358:1305-15.

4. Panday MR, Upadhyaya LR, Dhungel S, Pillaik K, Regmi HN, Neupane RP. Prevalence of hypertension in a rural community in Nepal. Indian Heart J 1981; 33:284-89.

5. Vaidya A, Pathak RP, Pandey MR. Prevalence of Hypertension in Nepalease community triples in 25 years: a repeat cross- sectional study in rural Kathmandu. Indian Hear Journal 2012; 6402:128-131.

6. Sharma D, Bkc M, Rajbhandari S, Raut R, Baidya SG, Kafle PM et al. Prevalence, awareness and control of hypertension in a suburban area of Kathmandu, Nepal. Indian Heart J 2006; 58:34-37.

7. Chobanian AV, Bakris GL, Black HR, Cushman WC, Green LA, Izzo JL. Jr, et al. National Heart, Lung and Blood Institute Joint National Committee on Prevention, Detection, Evaluation and treatment of High Blood Pressure: National High Blood Pressure Education Program Coordinating Committee. The Seventh Report of the joint National Committee on Prevention, Detection, Evaluation and Treatment of the High Blood Pressure: the JNC 7 report. JAMA 2003; 289:2560-72.

8. Shanthirani CS, Pradeepa R, Deepa R. Prevalence and risk factors of hypertension in a selected South Indian population-the Chennai Urban Population Study. J Assoc Physicians India 2003; 51:20-7.

9. Velazquez MO, Rosas PM, Lara EA. Arterial hypertension in Mexico: results of the National Health Survey 2000. Arch Cardiol Mex 2002; 72:71-84. at least once a week was negatively associated with the prevalence of the hypertension.

The main recommendations of this study are to establish - screening programs for early detection of hypertension and to develop health promotion programs to encourage behavior change for prevention and control of hypertension in this age group.

\section{ACKNOWLEDGEMENT}

We would like to extend our heartfelt thanks to participants for their valuable contribution in this research. We are grateful to Mr. Krisna Prasad Kayastha, Administritive officer of Banepa Municipality for supporting us for data collection. Our thanks also go to Mr. Ram Kumar Adhikari for his help in statistical analysis.

10. Joffres MR, Ghadirian P, Foder JG. Awareness, treatment, and control of hypertension in Canada. Am J Hypertens 1997; 10: 1097-102.

11. Stein AD, Stoyanovsky V, Mincheva V. Prevalence, awareness, treatment and control of hypertension in a working Bulgarian population. Eur J Epidemiol 2000; 16:265-70.

12. Sonmez HM, Basak O, Camci C. The epidemiology of elevated blood pressure as an estimate for hypertension in Aydin, Turkey. J Hum Hypertens 1999; 13:399-404.

13. Jenei Z, Pall D, Katona E. The epidemiology of hypertension and its associated risk factors in the city of Debrecen, Hungary. Public Health 2002; 116:138-44.

14. Tsai PS, Ke TL, Huang CJ. Prevalence and determinants of prehypertension status in the Taiwanese general population.J Hypertens 2005; 23:1355-60.

15. Kunz I, Schorr U, Klaus S. Resting metabolic rate and substrateuse in obesity hypertension. Hypertension 2000; 36:26-32.

16. Racial/ethnic disparities in prevalence, treatment, and control of hypertension - United States, 1999-2002. MMWR Morb Mortal Wkly Rep 2005; 54:7-9.

17. Onal $A E$, Erbil $S$, Ozel $S$. The prevalence of and risk factors for hypertension in adults living in Istanbul. Blood Press 2004; 13:31-6.

18. Erem C, Yıldız R, Kavgacı H. Prevalence of diabetes, obesity and hypertension in a Turkish population (Trabzon City). Diab Res Clin Pract 2001; 54:203-8.

19. Choi KM, Park HS, Han JH. Prevalence of prehypertensionand hypertension in a Korean population: KoreanNational Health and Nutrition Survey 2001. J Hypertens 2006; 24:1515-21.

20. Lai SW, Li TC, Lin CC. Hypertension and its related factors in Taiwanese elderly people. Yale J Biol Med 2001; 74:89-94. 